\title{
Estratégias de adaptação frente a ressacas marítimas provenientes de mudanças climáticas: $\mathbf{O}$ caso de Ponta da Praia, cidade de Santos - SP
}

Adaptation strategies in the face of undertows caused by climate change: The case of Ponta da Praia, city of Santos - SP

Estrategias de adaptación frente al oleaje provocado por el cambio climático: el caso de Ponta da Praia, ciudad de Santos - SP

Giovana Gravellos Dias Starke Rodrigues

Graduanda no curso de Arquitetura e Urbanismo pela Universidade Presbiteriana Mackenzie, São Paulo, Brasil. giovanastarke@hotmail.com

Paula von Zeska de Toledo

Arquiteta e Urbanista - Universidade Presbiteriana Mackenzie. Aluna especial - Cidades e Mudanças Climáticas da Pós-

Graduação da Universidade de São Paulo (FAU-USP), São Paulo, Brasil paulavonzeska@gmail.com

\section{Carlos Andrés Hernández Arriagada}

Orientador Doutor Arquiteto e Urbanista, Pesquisador e Professor na Faculdade de Arquitetura e Urbanismo Universidade Presbiteriana Mackenzie - Laboratório de Estratégias Projetuais (LABSTRATEGY), Pós Doutorando Núcleo Cidades Globais - IEA USP. São Paulo, Brasil. Professor visitante da Pós- graduação do curso de Arquitetura, Urbanismo e Geografia da Universidade de Concepción, Chile. carlos.arriagada@mackenzie.br / carlos.hernandez@usp.br 


\section{Periódica Téenica e Cientifica \\ Cidades Verdes}

ISSN eletrônico 2317-8604, volume 9, número 24, 2021

\section{RESUMO}

A pesquisa busca analisar e compreender de que maneira a aplicação de medidas adaptativas no território pode atenuar os impactos climáticos advindos da elevação do nível dos oceanos na cidade de Santos, São Paulo. Dessa maneira, ao estudar o bairro da Ponta da Praia, são estabelecidos critérios e macroestratégias de melhorias para o local, a fim de evitar possíveis futuros desastres ambientais. Para isso, a investigação se dá com uma análise territorial e geográfica, junto ao estudo das problemáticas locais, como a erosão costeira, de maneira que a discussão temática busque compreender quais as melhores medidas adaptativas, levando em consideração sua funcionalidade frente às questões climáticas e fragilidades da borda costeira. Medidas adaptativas e mitigadoras frente a mudanças climáticas auxiliam na redução de impactos futuros à população, reduzindo custos para reparo de danos e prolongando a segurança dos habitantes.

PALAVRAS-CHAVE: Estratégias. Mudanças Climáticas. Ressacas.

\section{ABSTRACT}

The research aims to analyze and understand how the application of adaptive measures in the territory can mitigate the climatic impacts arising from the rise in the level of the oceans in the city of Santos, São Paulo. In this way, when studying the Ponta da Praia neighborhood, criteria and macro-strategies for improvement are established for the site, in order to avoid possible future environmental disasters. For this, the investigation takes place with a territorial and geographical analysis, together with the study of local problems, such as coastal erosion, so that the thematic discussion seeks to understand which are the best adaptive measures, taking into account their functionality in relation to climatic and environmental issues. weaknesses of the coastal edge. Adaptive and mitigating measures for climate change helps to reduce future impacts on the population, reducing costs for repairing damage and prolonging the safety of the inhabitants.

KEY WORDS: Strategies. Climate Changes. Undertows.

\section{RESUMÉN}

La investigación busca analizar y comprender cómo la aplicación de medidas adaptativas en el territorio puede mitigar los impactos climáticos derivados del aumento del nivel de los océanos en la ciudad de Santos, São Paulo. De esta manera, al estudiar el barrio de Ponta da Praia, se establecen criterios y macroestrategias de mejora para el sitio, con el fin de evitar posibles desastres ambientales en el futuro. Para eso, la investigación se realiza con un análisis territorial y geográfico, junto con el estudio de problemas locales, como la erosión costera, por lo que la discusión temática busca entender cuáles son las mejores medidas adaptativas, teniendo en cuenta su funcionalidad en relación con cuestiones climáticas y medioambientales debilidades del borde costero. Las medidas de adaptación y mitigación ante el cambio climático ayudan a reducir los impactos futuros sobre la población, reduciendo los costos de reparación de los daños y prolongando la seguridad de los habitantes.

PALABRAS CLAVE: Estrategias. Cambios Climáticos. Resacas. 


\section{Periódica Téenica e Cientifica \\ Cidades Verdes}

ISSN eletrônico 2317-8604, volume 9, número 24, 2021

\section{INTRODUÇÃO}

As mudanças climáticas levaram ao aumento da temperatura global, assim como aumento de eventos extremos ${ }^{1}$ como secas, ondas de calor e elevação do nível dos oceanos. Segundo relatório de 2021 do Programa das Nações Unidas para o Meio Ambiente (UNEP), o ano de 2020 está entre um dos mais quentes já registrados, com efeitos climáticos afetando mais de 50 milhões de pessoas.

O nível dos oceanos é impactado diretamente pela expansão das águas e perda de gelo ártico, ambos causados pelo aumento da temperatura média. É esperado que até 2050 o nível médio do mar (NMM) aumente em 30 centímetros em RCP22 2.6 e 40 centímetros em RCP 8.5. Após 2050 as incertezas sobre os cenários aumentam, porém, seguindo as projeções de RCP o NMM é projetado para 0.59 metros em RCP 2.6 e 1.10 metros em RCP 8.5. (IPCC, 2019)

Medidas Mitigatórias e Adaptativas auxiliam no enfrentamento das mudanças climáticas. A mitigação visa reduzir a emissão de Gases do efeito estufa (GEE) e a redução de outras práticas de impacto ambiental. Segundo o Assesment Report 5 (AR5) do Painel Intergovernamental de Mudanças Climáticas da ONU (IPCC), a adaptação é o processo de ajuste a mudanças climáticas atuais ou futuras, reduzindo ou evitando danos causados por essas. Medidas adaptativas usadas de maneira local e combinada com análise e planejamento público auxiliam no enfrentamento da elevação do nível dos oceanos.

Medidas adaptativas variam conforme a localidade de aplicação, para isso deve-se avaliar e entender os riscos locais a fim de implantá-las. A World Wildlife Fund (WWF) exemplifica algumas medidas adaptativas, como: variar colheitas para tolerar climas mais secos e quentes; garantir que a infraestrutura local tolera climas extremos; ajudar comunidades a reduzir os riscos de elevação dos oceanos e aumento de inundações; e manejar os recursos de água e comida no contexto de mudança climática.

O processo de adaptação ajuda a reduzir riscos em qualquer cenário de temperatura (Figura 01) e, quando bem desenhado, é extremamente efetivo diminuindo custos de reparos em áreas bem urbanizadas e populosas. A falta dessas medidas pode aumentar os estragos causados por inundações na ordem de 2-3 até 2010, uma vez que eventos extremos dos oceanos serão mais frequentes. (IPPC, 2019; UNEP, 2021)

Figura 01: Cenários climáticos e planos de adaptação.

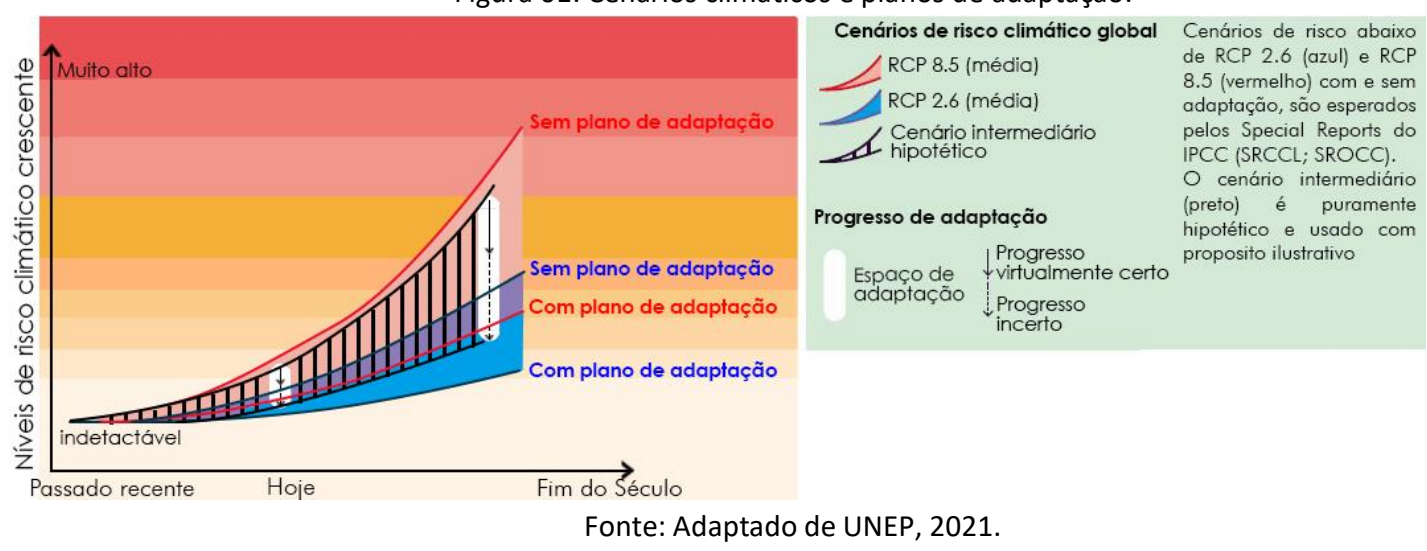

\footnotetext{
${ }^{1}$ Evidências apontam mudanças climáticas extremas a partir da metade do século XX. (IPCC,2012)

${ }^{2}$ RCP ou Representative Concentration Pathway são quatro cenários climáticos estabelecidos em 2011 na publicação "Special Issue: The Representative Concentration Pathways in Climatic Change" do IPCC sendo 2.6 o mais otimista em relação a medidas de mitigação e o 8.5 o menos otimista.
} 


\section{Cidades Verdes}

ISSN eletrônico 2317-8604, volume 9, número 24, 2021

\section{OBJETIVO}

A pesquisa tem como objetivo analisar a relação da elevação do nível dos oceanos prevista e medidas adaptativas, buscando entender como isso impactará a cidade de Santos, São Paulo. A escolha se dá por ser considerada a maior cidade do litoral paulista, com cerca de 433 mil habitantes, segundo dados estimativos de 2020 do IBGE. Situada a $72 \mathrm{~km}$ da capital paulista, a cidade abriga o maior porto da América Latina e é famosa pelos $7 \mathrm{~km}$ de praia, que se estende da Ponta da Praia (Figura 02) ao Emissário Submarino.

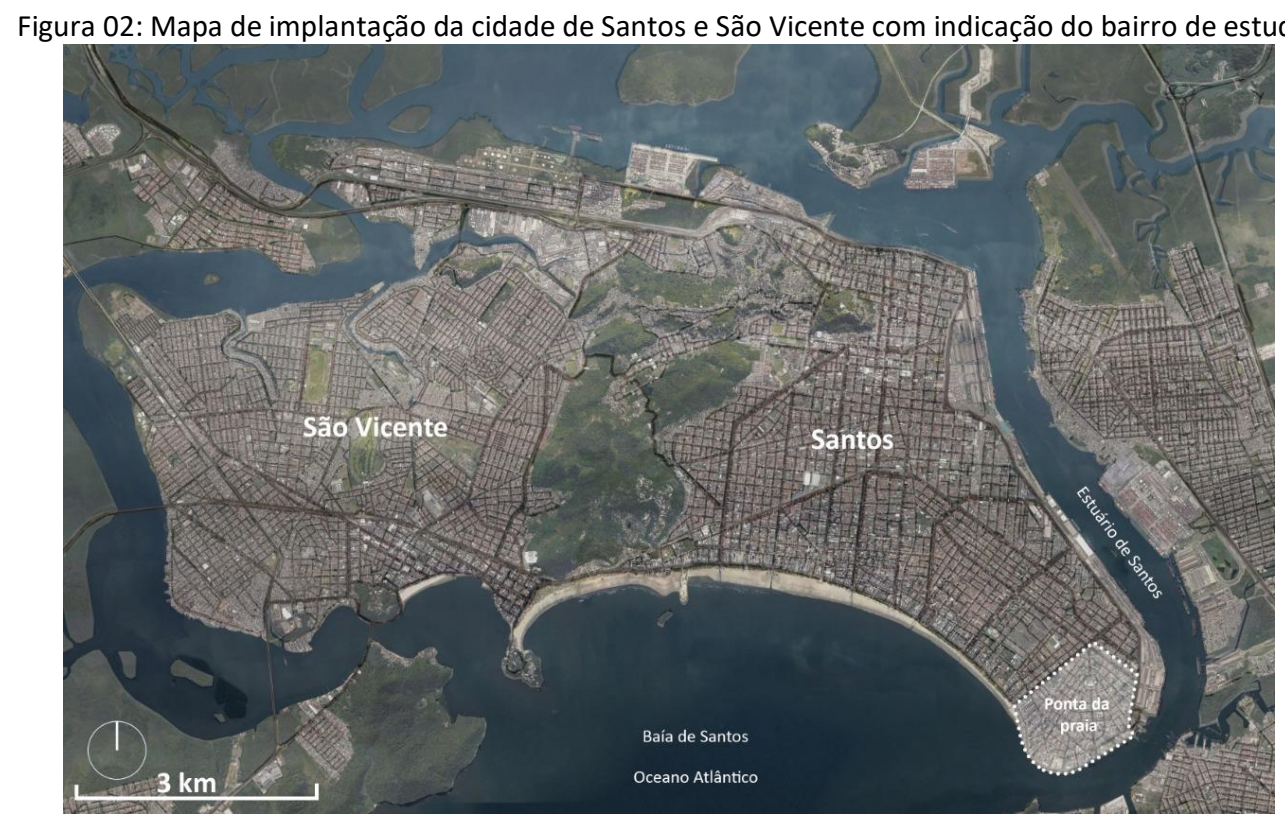

Fonte: Elaborada pelos autores com base no Google Earth.

A investigação se debruça sobre o patrimônio geográfico local e leva em consideração os aspectos oriundos das mudanças climáticas que, como aponta o Plano Municipal de Mudanças Climáticas de Santos (PMMCS, 2016), começaram a ser mais notáveis a partir de 2000, sendo que, entre as décadas de 1960 e 1990, as ocorrências de ressaca não passavam de 4 episódios por ano.

Ao entender a geografia e ocupação urbana da área será possível estabelecer critérios de melhoria para evitar futuros desastres, avaliando as características do setor impactado, tanto no âmbito da sua conformação territorial quanto espacial. Além disso, busca entender as possíveis interferências costeiras advindas do provável aumento do nível dos oceanos, ressacas, intempéries climáticas, como ciclones bomba, e os impactos frente à ocupação desta área litoral da cidade.

Para isso, a pesquisa trata de estabelecer macroestratégias como possíveis soluções para futuros protocolos litorâneos, seguindo o trabalho "Territórios frágeis em intempérie Eventos climáticos extremos em época de pandemia: o caso de Florianópolis" debatido inicialmente no Instituto de Estudos Avançados da Universidade de São Paulo (IEA-USP), tendo a seguinte pergunta norteadora como elemento estruturador:

"Quais são as atuais macroestratégias de contenção e preservação que possam ser aplicadas na borda costeira da cidade de Santos que permitam gerar adaptações geográficas frentes aos atuais impactos climáticos e marítimos?" 


\section{Periódica Téenica e Cientifica}

\section{Cidades Verdes}

ISSN eletrônico 2317-8604, volume 9, número 24, 2021

\section{METODOLOGIA}

A metodologia se constitui da revisão bibliográfica de estudos e análises publicadas que se relacionam com o tema, visita de campo e elaboração de mapa de estratégias projetuais;

- Análise dos dados publicados pelo Painel Intergovernamental sobre Mudanças Climáticas (IPCC) da ONU: O IPCC compila dados climáticos permitindo a projeção de cenários futuros. O AR5, de 2014, apresenta diversos aspectos referentes a mudanças climáticas e o Special Report on the Ocean and Cryosphere in a Changing Climate de 2019 foca nas mudanças que ocorrerão nos oceanos;

- Análise de estudos feitos na região da Ponta da Praia, em Santos, pela Universidade Estadual de Campinas (UNICAMP) e Universidade de São Paulo (USP) relativo a obras e projetos para contenção de ressacas marítimas: Ambos estudos foram realizados em 2017 e apresentam análise de impacto das ressacas na região estudada bem como análise dos projetos a serem aplicados;

- Visita de campo para averiguação do problema e registro da ressaca "in loco" de 2016, considerado o maior impacto climático que atingiu a área de estudo;

- Elaboração de mapa de estratégias projetuais do local estudado, aplicando a Metodologia de Estratégias Projetuais - MEP apresentada por Arriagada, 2012.

Têm-se como finalidade mapear os atuais dados climatológicos desde 2016 para a cidade de Santos e propor possíveis medidas de mitigação para a área estudada por meio da aplicação de macro estratégias, que considerará o Plano Municipal de Mudanças do Clima de Santos (PMMCS).

\section{AUMENTO DO NÍVEL DO MAR}

Desde 1993 o nível médio do mar aumenta em 3.3 mm/ano e, com o passar do tempo, essa média vem aumentando por conta do degelo do manto de gelo. Foi observado que em 2020 essa taxa continuou subindo. As regiões mais afetadas foram as do hemisfério sul, principalmente o leste de Madagascar (Oceano Índico), o leste da Nova Zelândia (Oceano Pacífico) e o leste do Rio de La Prata (Oceano Atlântico), uma vez que o aumento não é uniforme. (WMO, 2021)

Wang et. al (2021) analisaram dados já coletados de satélites de altimetria e compararam com as projeções feitas para o aumento do nível médio do mar a fim de averiguar a veracidade das projeções (Figura 03). Com dados de 2007-2018, é possível observar a similaridade do projetado com o que de fato ocorreu e essa comparação demonstra que os cenários de RCP 4.5 (considerado intermediário) e 8.5 (considerado pessimista) são os que estão de fato se concretizando. Sendo assim, serão utilizados os dois cenários climáticos aplicados à elevação dos oceanos nos resultados do estudo de caso apresentado. 


\section{Periódica Téenica e Cientifica}

\section{Cidades Verdes}

ISSN eletrônico 2317-8604, volume 9, número 24, 2021

Figura 03: Comparação entre observação de satélites e projeções meteorológicas.

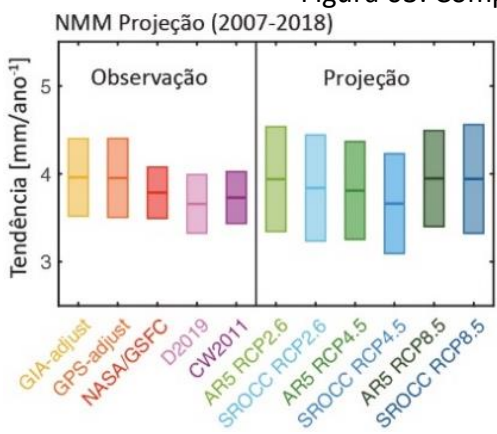

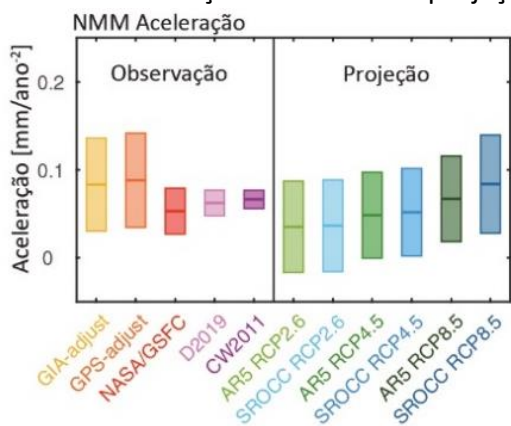

Fonte: Adaptado de Wang et. al, 2021.
Observação (Altimetria

GIA- adjust (Glacial isostatic adjustment)

GPS -adjust (Global Positioning System

NASA/GSFC National Aeronautics

and Space admininistration

D2019

CW2011

Projeção

AR5 (Assessment Report 5 IPCC)

SROCC (Special Report on the Ocean and Cryosphere in a Changing Climate IPCC)

\section{O CASO DE SANTOS - SÃO PAULO, BRASIL}

Baseado na linha do tempo elaborada (Figura 04), é perceptível que, com a constante ocupação da orla e crescente urbanização da Ponta da Praia, os fenômenos das ressacas marítimas começaram a se tornar mais perceptíveis e ocorrentes a partir dos anos 2000. Dessa forma, com as notáveis mudanças climáticas ocorridas durante os anos, a elevação do nível do mar fez com que os eventos de altas marés ficassem mais alarmantes para a região, tendo registro mais grave no ano de 2016.



Fonte: Elaborada pelos autores com base em PMMCS, 2016.

Ao decorrer dos últimos 60 anos, a faixa de areia do bairro da Ponta da Praia vem perdendo cada vez mais área, totalizando uma perda de cerca de $33 \mathrm{mil} \mathrm{m}^{2}$ de 1962 a 2014 (Figura 05), acarretando uma modificação costeira que tem como causas principais o aumento do nível do mar e intervenções antrópicas ${ }^{3}$, ambos considerados prejudiciais para o local. Essas situações geram danos para a infraestrutura urbana, como: destruição das muretas, que são um 'marco' da cidade ${ }^{4}$, e invasão do mar em calçadas e avenidas importantes, levando destroços e água para térreos de prédios, restaurantes, clubes, entre outros usos. Além de que gera uma perda de paisagem, no caso de o nível do mar se elevar a ponto de fazer desaparecer uma porção da faixa de areia, prejudicando a função social da praia.

\footnotetext{
${ }^{3}$ Relativo ao homem ou ao período de existência do homem na Terra e às modificações por ele provocadas no meio ambiente. (ANTRÓPICO, 2021)

${ }^{4}$ Construídas na década de 1940, hoje são consideradas "signo visual da identidade santista". (PREFEITURA,2019)
} 


\section{Cidades Verdes}

ISSN eletrônico 2317-8604, volume 9, número 24, 2021

Figura 05: Imagens aéreas da região entre o Canal 6 e a Ponta da Praia, em Santos, mostrando a evolução da faixa de areia ao longo dos anos.

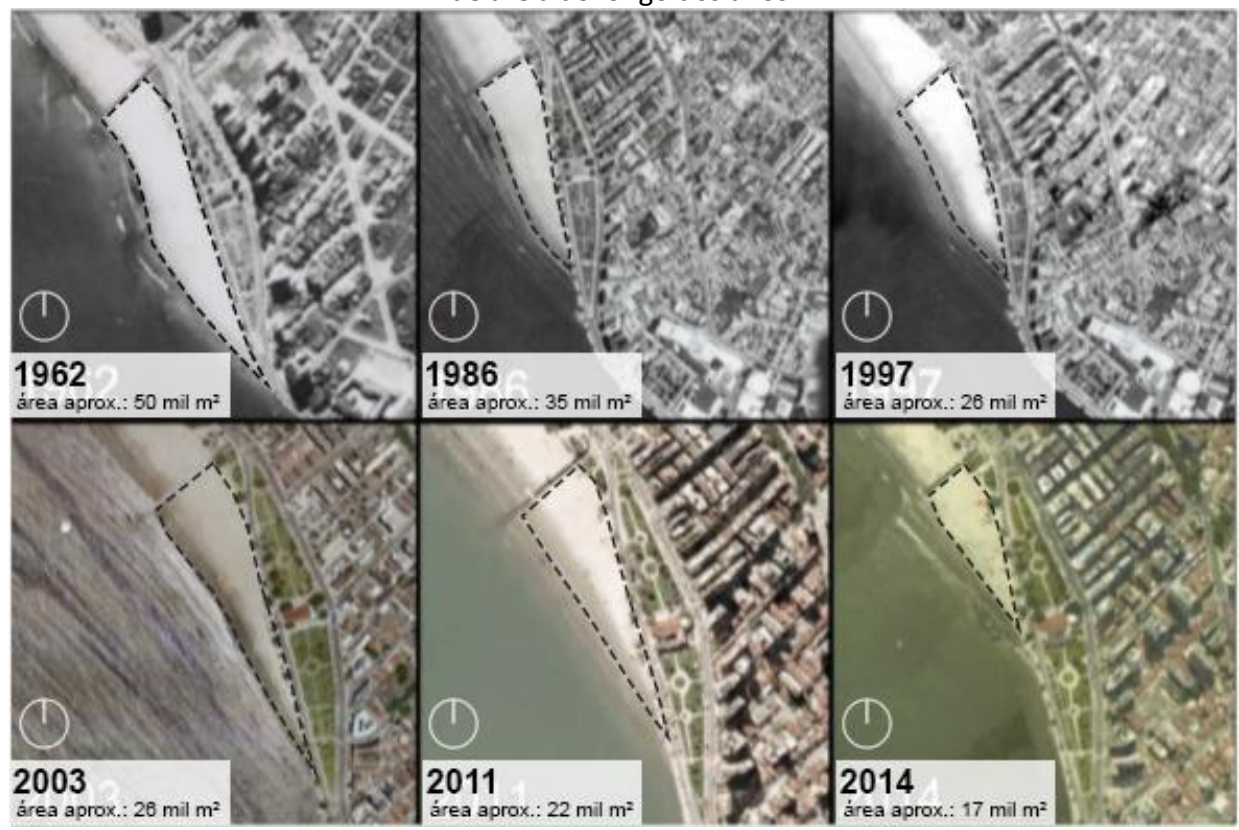

Fonte: Oliveira, Leonardo (2018). Modificado pelos autores.

A erosão costeira ${ }^{5}$, processo que ocorre nessa região, causa um desgaste natural do solo e, neste cenário, é atribuído à ação da água, como elevação do nível do mar ou modificação do clima de ondas, e atividades humanas que resultam no desgaste ou remoção deste solo. Dessa forma, o balanço sedimentar é negativo, ou seja, o local perde mais sedimentos do que recebe, tendo como principal consequência o recuo da linha de costa, diminuindo cada vez mais o território de praia.

Gireli, Garcia e Campos (2017) discorrem que a região da Ponta da Praia possuía, em meados do século $X X$, uma extensa faixa de areia que foi sendo perdida ao longo do tempo. Ainda assim, as observações de campo mostram uma aceleração deste processo de erosão costeira desde 2010, que passou a apresentar, nas áreas mais afetadas, uma taxa de recuo superior a 6 metros por ano.

De acordo com Oliveira (2017), uma outra característica é que, diferente de toda a orla da cidade - do Canal 1 ao Canal 6 -, a região da Ponta da Praia não apresenta os jardins da orla, reconhecido símbolo urbano da cidade. Sendo assim, Suguio (1980) explica que esses jardins seriam como um pós-praia, região fora do alcance das ondas e marés normais, somente alcançada pela água com a ocorrência de marés muito altas.

\subsection{CAUSAS E CONSEQUÊNCIAS DA EROSÃO COSTEIRA}

Como citado anteriormente, uma das causas principais do que vem acontecendo na Ponta da Praia são as intervenções antrópicas, que, nesse caso, tem relação com a dragagem sistemática do canal do estuário, intervenção no sistema natural que não é visível. A situação se agrava quando o sedimento removido pelo processo de dragagem passa a ser descartado fora do sistema natural de onde foi removido, como neste caso, diminuindo consideravelmente a disponibilidade de areia na área de foz do canal de maré (OLIVEIRA, 2017).

\footnotetext{
${ }^{5}$ A erosão costeira ocorre quando a praia perde mais sedimentos do que recebe. (IOUSP, 2021)
} 
"A mudança da morfologia ${ }^{6}$ submarina causada por este mesmo processo permite a chegada de 245 ondas cada vez maiores na costa, uma vez que a morfologia submarina não é mais dissipativa." (OLIVEIRA, 2017, p. 244)

Como discorre Oliveira (2017, p. 243), "no caso dos procedimentos de dragagem do Porto de Santos, as normas técnicas determinam que o descarte deve ser feito fora da baía de Santos, em uma área marinha selecionada para tal". Sendo assim, esse procedimento faz com que todo o material dragado seja despejado fora do sistema sedimentar ${ }^{7}$ do canal estuarino e da costa de Santos, provocando uma falta de sedimento de grandes proporções na Ponta da Praia e regiões próximas.

Além disso, intervenções antrópicas como alta urbanização, fator que interrompe a dinâmica natural do sistema praial, somados a não existência de uma região pós-praia (jardim da orla), faz com que os eventos de marés altas e ressacas marítimas atinjam diretamente essa porção da cidade já urbanizada. Esse fator afeta diretamente a Ponta da Praia e, se houver um possível descontrole desses processos, consequentemente pode haver um aumento das chances de impactos climáticos nessa borda da cidade.

Gireli, Garcia e Campos (2017) apontam que atualmente a Ponta da Praia encontra-se em condições críticas de erosão, acarretando, cada vez mais, na diminuição da faixa de areia, mesmo contando com intervenções emergenciais locais efetuadas pela Prefeitura de Santos. Essas intervenções consistem na alimentação artificial de areia, retiradas dos canais 2 e 3, e levadas até a área em questão através de caminhões. Tal metodologia se mostra ineficaz frente a capacidade erosiva, sendo que, em um só evento de ressaca marítima, todo esse sedimento depositado é remobilizado, além de que o processo transporta uma quantidade de areia muito abaixo do que é necessário para compensar o montante retirado pelo processo erosivo.

Outra intervenção realizada pela Prefeitura de Santos que também se mostra ineficaz para o tamanho problema da região é a colocação de pedras posicionadas rentes aos muros de praia, a fim de proteger as estruturas existentes. Essa proteção de enrocamento dos muros de pedra foi subdimensionada de forma que não protege adequadamente a infraestrutura urbana, sendo medidas aplicadas sem estudos técnicos.

\footnotetext{
“Desde o recuo mais significativo do perfil praial, ocorrido a partir de 2010, nota-se que a direção das ondas que incidem naquele trecho da praia é diferente da observada em anos anteriores. [...] Esta mudança de rumo da frente de ondas provocou uma reflexão das ondas incidentes junto das estruturas rígidas instaladas para evitar que as ondas danifiquem a avenida e obras adjacentes." (GIRELI; GARCIA; CAMPOS, 2017)
}

\section{RESSACA MARÍTIMA EM 2016}

No dia 21 de agosto de 2016 a cidade de Santos sofreu com a pior ressaca já registrada até então, com medições de ondas acima de $4,25 \mathrm{~m}$ no fim da tarde. $O$ evento aconteceu durante a passagem de uma frente fria com ventos de $40 \mathrm{~km} / \mathrm{h}$ a $90 \mathrm{~km} / \mathrm{h}$, fator que, em conjunto com a intensidade, pode potencializar a ressaca marítima, fazendo com que vire um acontecimento mais violento. Esse fenômeno gerou danos em toda a orla e forçou o Porto de Santos a

\footnotetext{
${ }^{6}$ Tratado da configuração externa que a matéria pode ter. (MORFOLOGIA, 2021)

${ }^{7}$ Material ou camada de material sólido, mineral ou orgânico, depositado por um agente de transporte, como a água, o gelo ou o vento. (SEDIMENTO, 2021)
} 


\section{Periódica Técnica e Cientifica}

\section{Cidades Verdes}

ISSN eletrônico 2317-8604, volume 9, número 24, 2021

permanecer fechado por pelo menos 30 horas, segundo G1 Santos (2016a).

O Sistema de Informações Meteo-oceanográficos em tempo real desenvolvido pela HidroMares ${ }^{8}, \mathrm{o} \mathrm{SISMO}^{\circledR}$, registrou dados inéditos desde que foi instalado no Porto de Santos (Figura 06 e 07):

Figura 06: Resultado das medições registradas no período da ressaca marítima - Nível do mar.

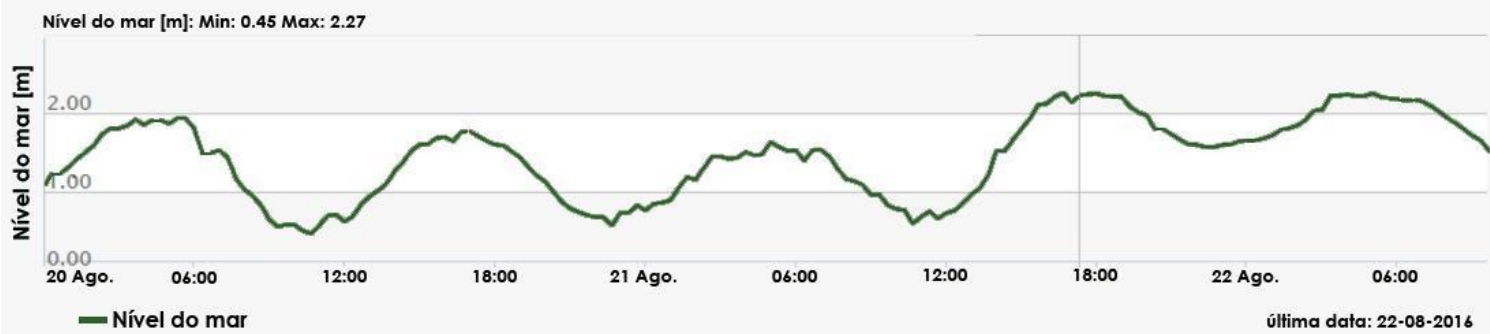

Fonte: Adaptado de Ressaca, 2016.

Figura 07: Resultado das medições registradas no período da ressaca marítima - Altura das ondas.

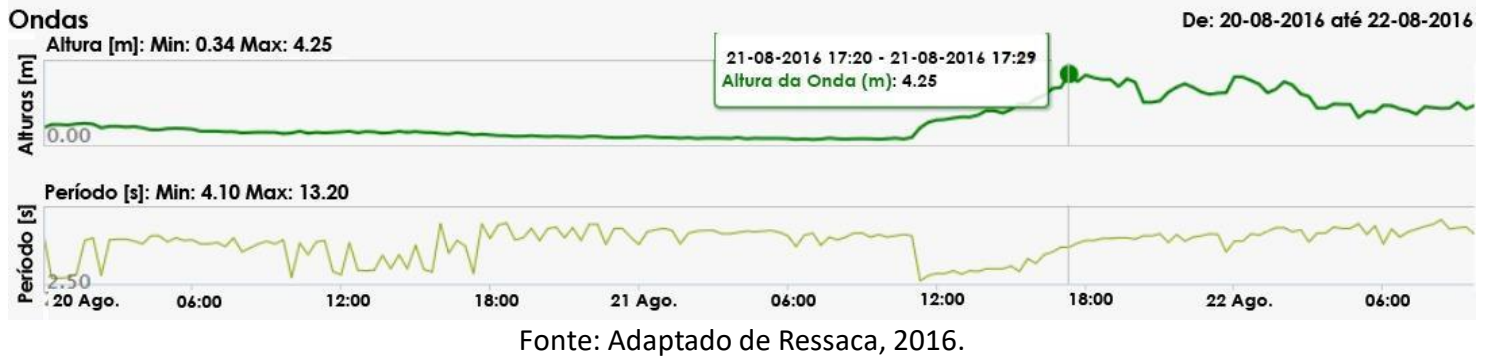

O acontecimento fez com que as duas pistas da avenida da praia, Av. Bartolomeu de Gusmão e Av. Almirante Saldanha da Gama, ficassem inundadas, causando interdições e estragos em diversos trechos (Figura 08 e 09). Por conta do alto volume de água, alguns prédios e empreendimento da orla tiveram os pavimentos térreos tomados pelo mar, com marcas de água que chegam a $80 \mathrm{~cm}$ de altura.

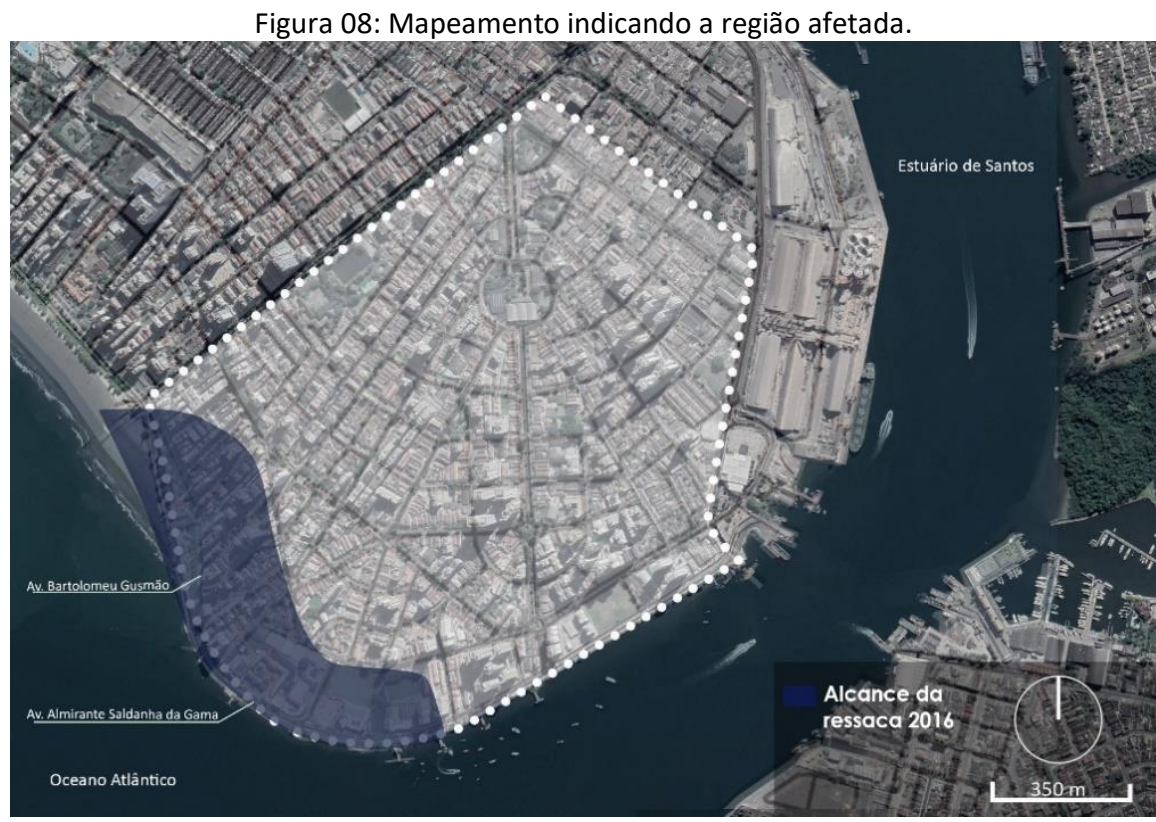

Fonte: Adaptado de Ressaca, 2016.

\footnotetext{
${ }^{8}$ A HidroMares atua no auxílio a praticamente todas as atividades ligadas aos oceanos, mares, rios e represas. (SOBRE NÓS, 2021)
} 


\section{Periódica Téenica e Cientifica}

\section{Cidades Verdes}

ISSN eletrônico 2317-8604, volume 9, número 24, 2021

A elevação de maré neste dia chegou a 2,60 m, causando danos também nos decks localizados nessa borda costeira, além de ter registro de uma embarcação que praticamente ficou à deriva e derrubou parte das muretas da orla. Além disso, salas do Museu de Pesca, localizado nesta área de risco, foram parcialmente destruídas.

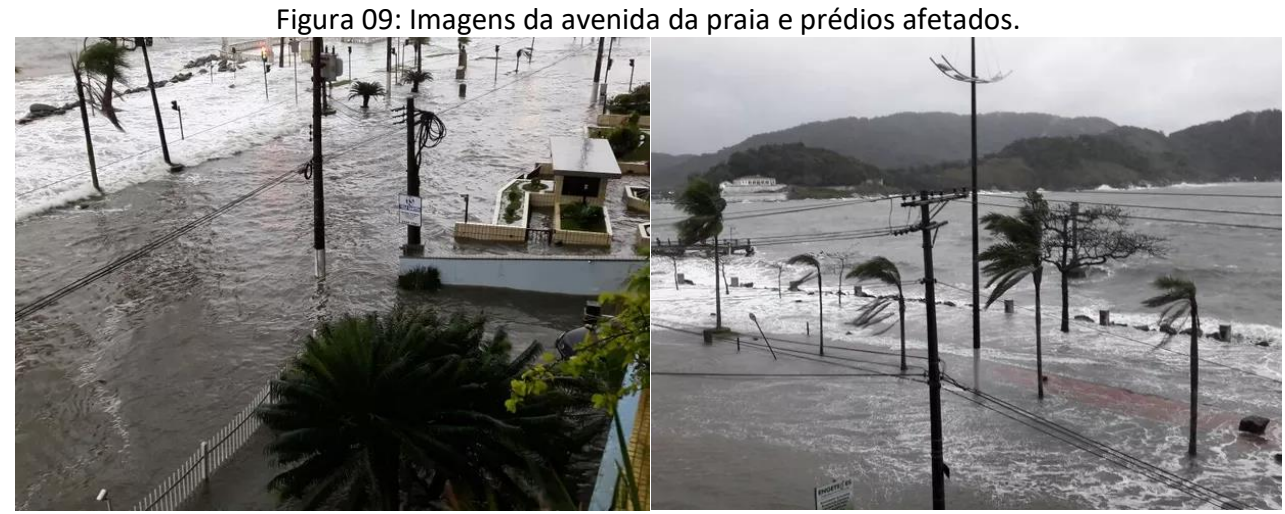

Foto: Carlos Martiniano. Fonte: G1 Santos, 2016b.

\section{MEDIDAS ADAPTATIVAS}

\subsection{PROJETO PILOTO: BARREIRAS SUBMERSAS - DESENVOLVIDO PELOS PESQUISADORES GIRELI, GARCIA E CAMPOS (2017) NO DEPARTAMENTO DE RECURSOS HÍDRICOS (DHR) DA UNIVERSIDADE ESTADUAL DE CAMPINAS (UNICAMP)}

A implantação de projetos-piloto visa diminuir os prejuízos causados na região, constituindo-se em alternativas viáveis a curto prazo. Além disso, tem por objetivo contribuir para ampliar o conhecimento sobre os impactos nas áreas e indicar intervenções mais definitivas para as regiões de maior impacto.

Sendo assim, como apresentam Gireli, Garcia e Campos (2017), a solução piloto proposta pela Universidade Estadual de Campinas (UNICAMP) consiste em um molhe parcialmente submerso construídos por geotubos ${ }^{9}$ e geobags ${ }^{10}$ preenchidos com areia da praia (Figura 10) de forma a: a. Reduzir o custo de implantação de uma solução definitiva, bem como o risco desta solução ter baixa eficácia e/ou produzir impactos indesejados em regiões adjacentes; b. Causar o mínimo impacto visual, visto que a área tem atrativo turístico; c. Permitir a execução da obra em curto período de tempo; d. Permitir uma fácil desmobilização da obra e a inexistência de impactos ambientais decorrentes de sua retirada, caso esta se mostre ineficiente.

\footnotetext{
${ }^{9}$ São tubos poliméricos perfurados ou não usados para drenagem de líquidos ou gases (incluindo coleta de chorume ou gases em aplicações de aterros sanitários). Em alguns casos o tubo perfurado é envolvido por um filtro geotêxtil. (CONSTRUÇÃOCIVILPET, 2016)

${ }^{10}$ Grandes bolsas de geotêxtil, aplicadas em projeto de proteção ambiental, no gerenciamento de resíduos sólidos e em contenção marítima. (NAKAMURA, c2021)
} 


\section{Periódica Téenica e Cientifica}

\section{Cidades Verdes}

ISSN eletrônico 2317-8604, volume 9, número 24, 2021

Figura 10: Posicionamento em planta da obra piloto.

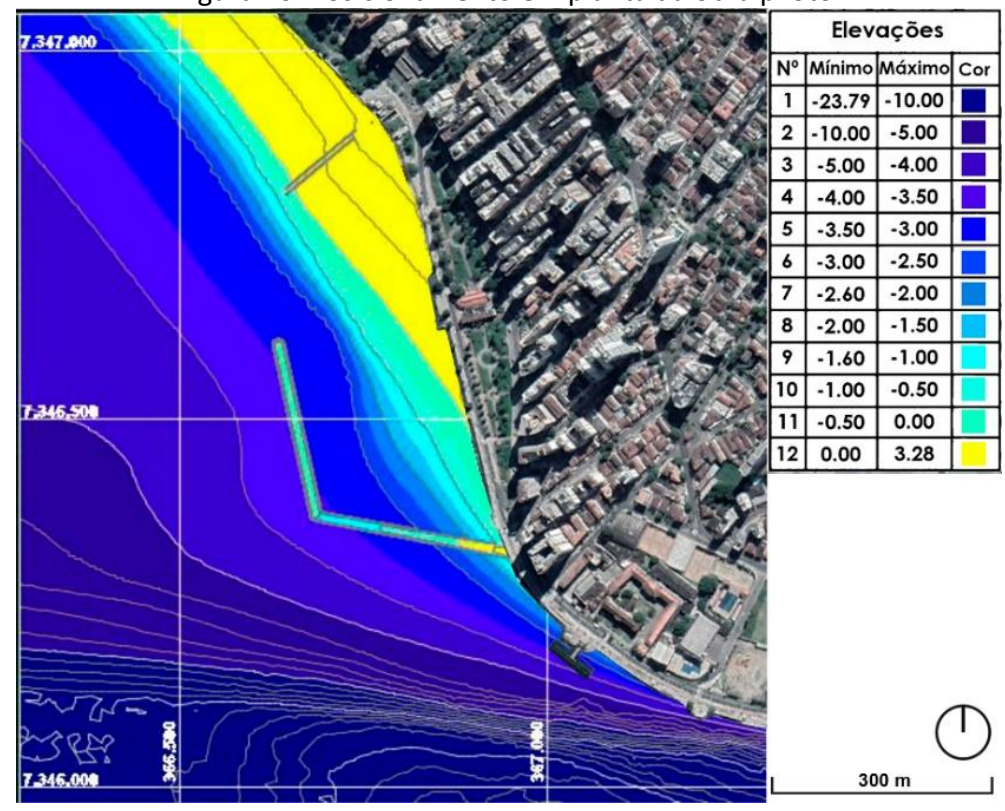

Fonte: Adaptado de Gireli, Garcia e Campos, 2017.

Portanto, levando em consideração esses fatores apresentados anteriormente, a proposta do projeto-piloto se constitui de dois segmentos lineares, sendo o primeiro enraizado junto ao muro de praia e o seguindo mar adentro por 275 metros (GIRELI; GARCIA; CAMPOS, 2017).

Esse primeiro segmento foi chamado de trecho transversal, concebido como uma linha única de geotubos que avançam mar adentro, com três funções principais, como apresentam Gireli, Garcia e Campos (2017): a. Reduzir de maneira significativa a velocidade das correntes de maré que se direcionam para a embocadura do estuário santista no trecho entre a obra e a linha de costa; b. Servir de proteção e dar suporte ao acúmulo de sedimentos que se espera que aconteça entre a obra proposta e a linha de costa atual; c. Permitir uma adequada circulação da corrente superficial, evitando assim a deterioração da qualidade da água e consequentemente da condição de balneabilidade no tardoz da obra (região entre a obra do projeto-piloto e a borda costeira).

O segundo segmento, chamado de longitudinal, foi implantado de forma a ficar paralelo à direção dos muros de proteção na Ponta da Praia. Segundo Gireli, Garcia e Campos (2017), espera-se que a refração das ondas que ocorrerá sobre a proteção proposta faça com que o rumo das ondas passe a atingir os muros com ângulo próximo à ortogonal, diminuindo o transporte longitudinal costeiro resultante. Além disso, optou-se por implantar esse segmento longitudinal de maneira a minimizar os efeitos da ressaca e que permitisse observar uma acresção de área de praia. 
Periódica Técnica e Cientifica

\section{Cidades Verdes}

ISSN eletrônico 2317-8604, volume 9, número 24, 2021

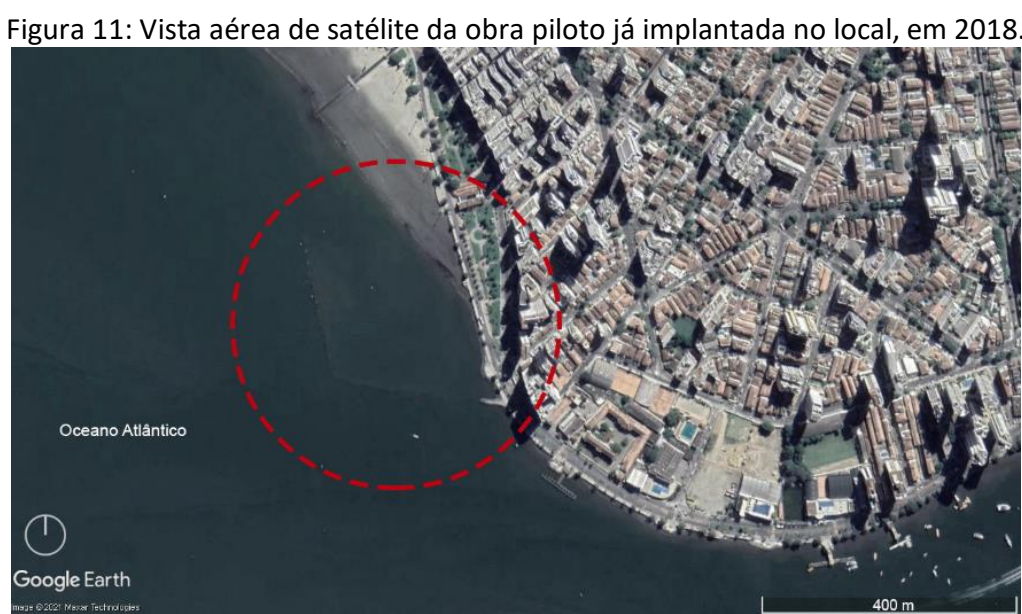

Fonte: Elaborada pelos autores com base no Google Earth.

\subsection{PROPOSTAS: OBRAS DE PROTEÇÃO DE COSTA - DESENVOLVIDAS PELOS PESQUISADORES PION, BERNARDINO E ZAMBON (2017) PELA FUNDAÇÃO CENTRO TECNOLÓGICO DE HIDRÁULICA (FCTH) DA UNIVERSIDADE DE SÃO PAULO (USP)}

As alternativas de intervenções de engenharia estudadas para a proteção da Ponta da Praia em Santos foram definidas a partir dos padrões de transporte sedimentar nesta região (Figura 12) (PION; BERNARDINO; ZAMBON, 2017)

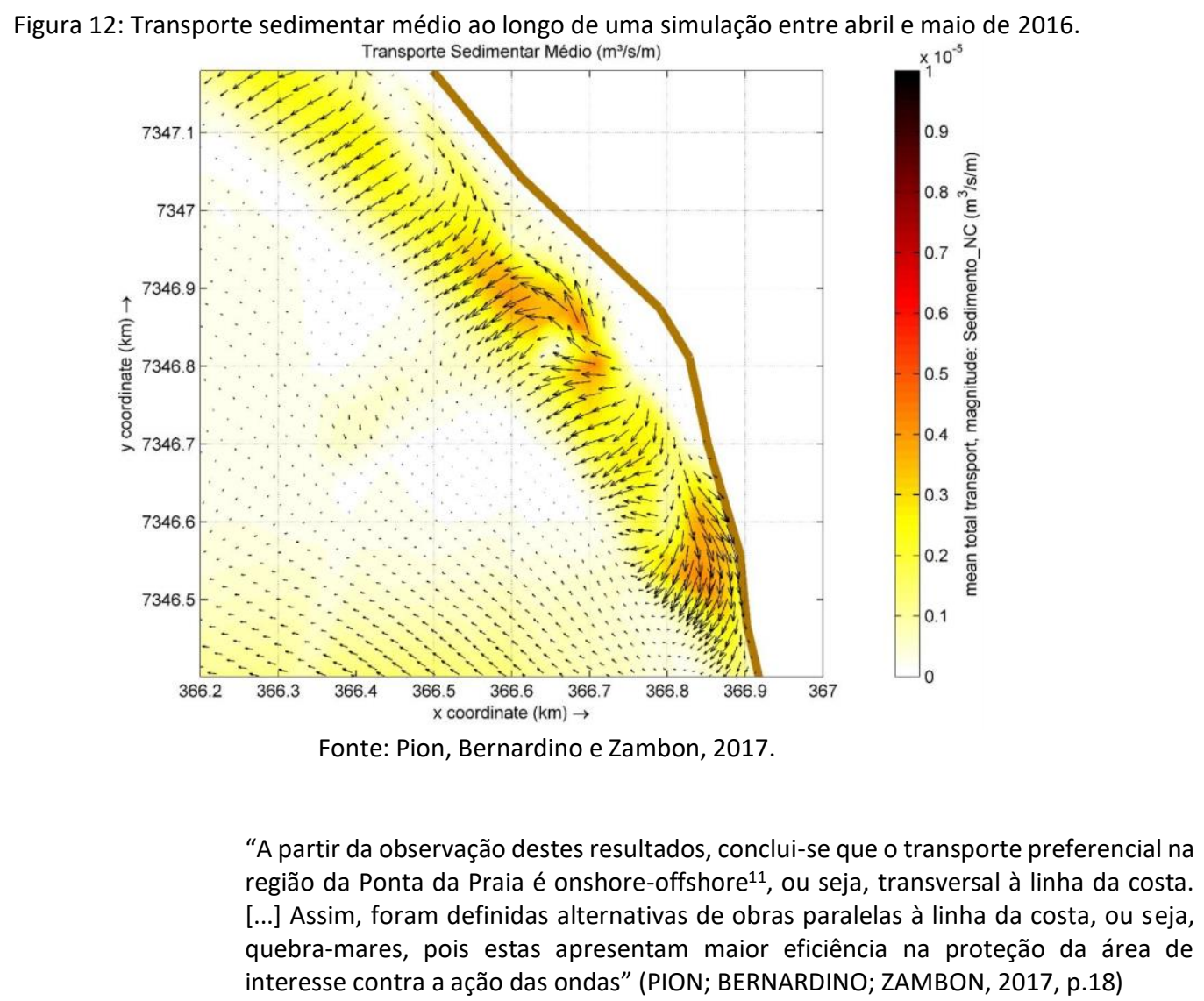

\footnotetext{
${ }^{11}$ Terminologia utilizada para definir se determinado serviço será realizado em área de continente (onshore) ou mar
} (offshore). (PORTO GENTE, 2016) 


\section{Periódica Téenica e Cientifica \\ Cidades Verdes}

ISSN eletrônico 2317-8604, volume 9, número 24, 2021

Pion, Bernardino e Zambon (2017) discorrem que, geralmente, os quebra-mares implantados para a proteção da costa são segmentados, possuindo aberturas que possibilitam a renovação da água que evitam a degradação da sua qualidade. Estas obras podem ser submersas (abaixo do nível da água) ou emersas (acima do nível da água). Dessa maneira, foram definidos quatro layouts de quebra-mares (Figura 13), considerando alternativas contínuas ou segmentadas. As alternativas contínuas foram consideradas submersas, enquanto as alternativas segmentadas são emersas, considerando as recomendações de U.S. Army (2006).

As alternativas 1 e 2 consistem em quebra-mares segmentados e emersos. A alternativa 1 localiza-se a 250 metros da linha de costa, aproximadamente na cota -2,0 metros, tendo seu início nas proximidades do Deck do Pescador e o primeiro segmento com 725 metros de extensão. Os demais segmentos têm 300 metros de comprimento e 100 metros de brecha entre eles, totalizando 1925 metros construídos. Já a alternativa 2 está localizada mais distante da linha de costa, aproximadamente na cota $-3,0$ metros. 0 primeiro segmento parte do mesmo local que a alternativa anterior, porém tem 700 metros de comprimento e os demais apresentam 150 metros, com espaçamento de 100 metros entre eles, totalizando 1700 metros construídos)

As demais alternativas, $1 \mathrm{~B}$ e $2 \mathrm{~B}$, consistem em quebra-mares contínuos e submersos. Ambos estão localizados nos mesmos alinhamentos das alternativas 1 e 2, e totalizam 2300 e 2250 metros, respectivamente.

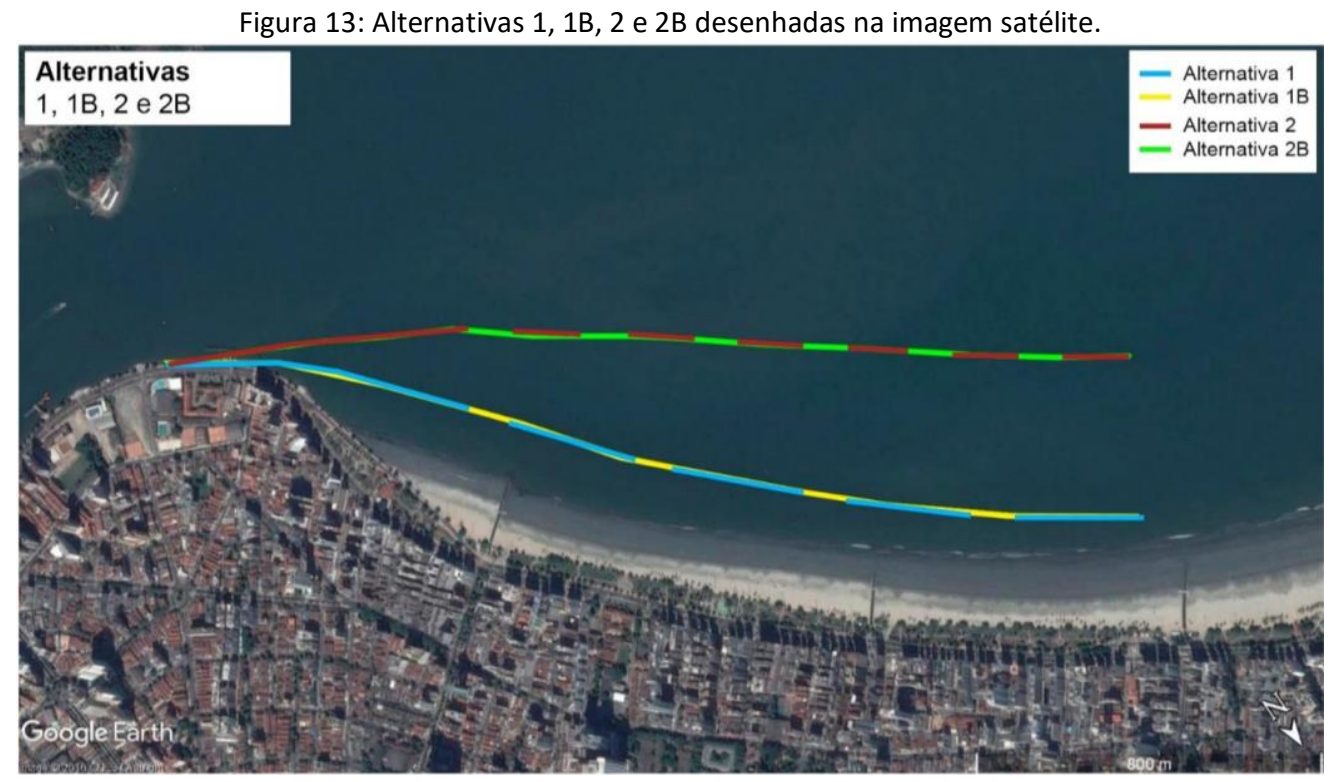

Fonte: Adaptado de Pion, Bernardino e Zambon, 2017.

Como explicam Pion, Bernardino e Zambon (2017), para o auxílio da tomada de decisão em relação à melhor alternativa, foi realizada uma matriz de decisão baseada em critérios a serem avaliados: redução de ondas, renovação de água, impactos na linha de costa e custo de implantação de obra. Cada item desse recebeu um peso de acordo com a relevância para a decisão de implantação da obra na Ponta da Praia, como aponta a tabela: 


\section{Periódica Téenica e Cientifica \\ Cidades Verdes}

ISSN eletrônico 2317-8604, volume 9, número 24, 2021

Tabela 1 - Matriz de Decisão indicando as alternativas mais eficientes

\begin{tabular}{|c|c|c|c|c|c|}
\hline Critério & Peso & $\begin{array}{c}\text { Alternativa } \\
1\end{array}$ & $\begin{array}{c}\text { Alternativa } \\
\text { 1B }\end{array}$ & $\begin{array}{c}\text { Alternativa } \\
\mathbf{2}\end{array}$ & $\begin{array}{c}\text { Alternativa } \\
\text { 2B }\end{array}$ \\
\hline Dissipação de Ondas & 2 & 8 & 4 & 1 & 2 \\
\hline Renovação de Água & 2 & 1 & 4 & 2 & 8 \\
\hline Alterações Morfológicas & 4 & 2 & 1 & 8 & 4 \\
\hline Custo & 1 & 2 & 8 & 1 & 4 \\
\hline Nota Final & & 28 & 28 & 39 & 40 \\
\hline
\end{tabular}

Fonte: Pion, Bernardino e Zambon, 2017. Adaptado pelos autores.

"As melhores alternativas, com notas finais muito próximas, foram as alternativas localizadas nas proximidades da isóbata de -3 metros, mais afastadas em relação à linha da costa. O resultado final destas alternativas foi definido pelo seu efeito nas proximidades da linha de costa e no transporte sedimentar médio. A alternativa 2 tende a provocar menores impactos na linha da costa em relação à condição atual. $A$ implantação da alternativa 2B provoca maior redução do transporte médio, podendo provocar preenchimento da área abrigada em longo prazo." (PION; BERNARDINO; ZAMBON, 2017, p. 46)

Segue, dessa maneira, as duas melhores alternativas ilustradas no gráfico:

Figura 14: Comparação de alternativas - Altura Significativa de Ondas - Atual x Alternativa 2 e 2B, respectivamente.

Altura Significativa de Ondas - Condição Atual - 27 abr 2016 9:00

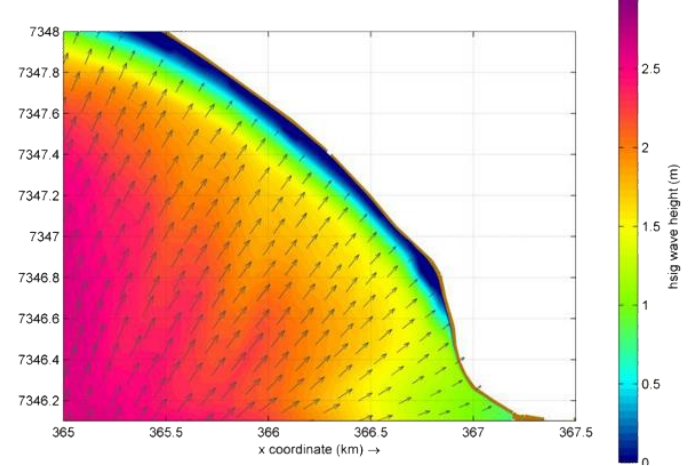

Altura Significativa de Ondas - Alternativa 2 - 27 abr 2016 9:00

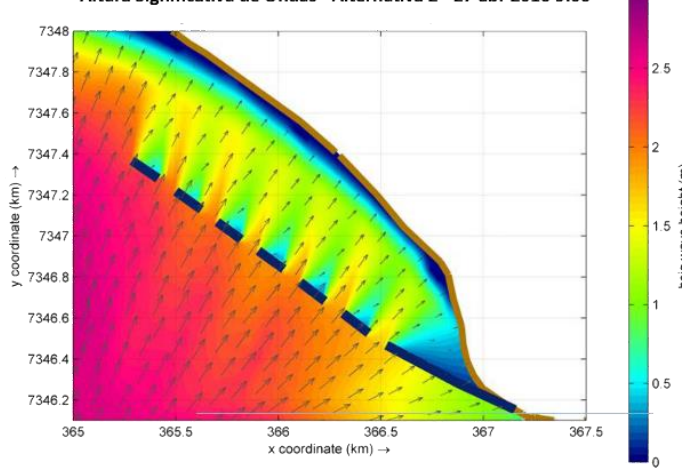

Altura Significativa de Ondas - Alternativa 2B - 27 abr 2016 9:00

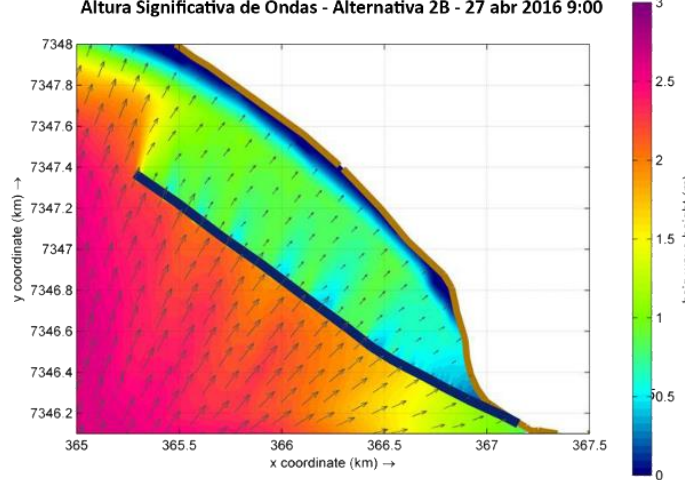

Fonte: Pion, Bernardino e Zambon, 2017.

\section{RESULTADOS}

Assim como discorre a engenheira civil Alexandra Sampaio, coordenadora do Núcleo de Pesquisas Hidrodinâmicas na Unisanta (NPH-Unisanta), sobre um caso mais recente de ressaca em Santos, em G1 Santos (2019), "para ressacas menos intensas, os geobags aparentemente funcionaram bem até agora, entretanto nos extremos já não é possível afirmar 


\section{Periódica Téenica e Cientifica}

\section{Cidades Verdes}

ISSN eletrônico 2317-8604, volume 9, número 24, 2021

sua eficiência pelo que foi observado". Dessa forma, acredita-se que as bags podem ter atenuado um pouco da energia das ondas, mas não o suficiente para conter as ressacas de marés muito elevadas, pois estas atravessam as estruturas implantadas no projeto-piloto realizado pela UNICAMP.

Portanto, tendo uma análise sobre o projeto-piloto com base nos acontecimentos de antes e depois da implantação das bags submersas, é possível perceber que, mesmo que as mesmas favoreçam a dissipação da energia das ondas e protejam a praia do processo de erosão, não são totalmente eficientes para eventos de marés altas e com ondas elevadas. Dessa forma, essa borda da Ponta da Praia ainda possui uma fragilidade frente os eventos de ressacas marítimas, visto que ainda sofre com galgamento (vazão da massa de água) e quebra das tão conhecidas muretas.

Quanto às propostas apresentadas pela USP, acredita-se que os molhes das alternativas 2 e 2B sirvam para melhor ajudar a região a combater os efeitos das altas marés, pois estas estão implantadas de uma maneira que protege um perímetro maior da Ponta da Praia, podendo minimizar com maior eficiência o galgamento que ocorre na borda costeira.

\section{CONCLUSÃO}

Ao fazer o uso da Metodologia de Estratégias Projetuais - MEP (Hernández Arriagada, 2012), é possível desenhar estratégias a partir de reflexões da pergunta norteadora:

"Quais são as atuais macroestratégias de contenção e preservação que possam ser aplicadas na borda costeira da cidade de Santos que permitam gerar adaptações geográficas frentes aos atuais impactos climáticos e marítimos?"

Para tal estudo, foram consideradas aplicações das seguintes macro estratégias na região (Figura 15):

1. Enchentes: Fenômeno caracterizado pela grande abundância ou fluidez no volume de águas, devido a excesso de chuvas ou subida de marés. Estabelecem-se as seguintes estratégias: a. Reservatórios de Contenção; b. Projetos Estratégicos Flutuantes; c. Ação de Atividades Cooperativas; d. Planejamento de Bacias Hidrográficas; e. Política de Gestão de Águas; f. Mapeamento de Sistemas Hidrológicos; g. Retirada de Moradores em Zonas de Risco;

2. Resiliência Pós-Desastre, como no caso de ressacas e eventos extremos, a seguir enumeradas: a. Mapeamento Pós Desastre; b. Suprimentos Emergenciais; c. Habitações Emergenciais para Desabrigados; d. Sistema de Aviso para Obtenção de Auxílios Diversos; e. Sistema de Logística Otimizado durante e Pós-Desastre, Garantindo Máxima Sobrevivência; f. Mobilização Social em Prol da Sobrevivência; g. Apoio Psicológico para População (Casos de Perdas); h. Projetos de Recuperação; i. Realocação da população; j. Sistema de Monitoramento; k. Módulos Avançados de Apoio Médico, I. Sistema de Aviso / Alarme que Funcione mesmo na Ausência de Energia Elétrica; m. Fontes Alternativas de Recursos (Água e Alimento); n. Ações de Médicos sem Fronteiras; o. Remodelação Populacional, Relocação Emergencial. 


\section{Periádica Técnica e Cientifica \\ Cidades Verdes}

ISSN eletrônico 2317-8604, volume 9, número 24, 2021

Figura 15: Mapa de estratégias aplicadas e projeção do aumento do nível médio do mar em 2100.



Fonte: Elaborada pelos autores com base no Google Earth.

Frente às escolhas de estratégias que irão promover a melhoria emergencial da localidade estudada, identificou-se como suporte às metas criadas no PMMCS (2016). 0 relatório divide-se em dois grupos de atividades programadas - Medidas Mitigadoras e Medidas Adaptativas - do qual pretende-se criar um projeto de lei para suas implantações.

Conforme as medidas tidas como mitigadoras do PMMCS (2016) e conforme correlacionado com as estratégias, escolheram-se como complementares para a funcionalidade das ações: a. Mitigação das ações humanas que possam favorecer a aceleração das mudanças no clima; b. Otimização do aproveitamento e redução dos resíduos; c. Otimização e redução da utilização dos recursos naturais nas cidades.

Além dessas, as medidas adaptativas buscam a diminuição do impacto na população, sendo elas, segundo o PMMCS (2016): a. Diagnóstico da situação atual das mudanças climáticas em Santos, contendo o mapeamento das vulnerabilidades e suscetibilidades aos impactos esperados; b. Capacitar a população para enfrentar as situações de riscos costeiros; c. Implantar ações de monitoramento contínuo e integrado para manutenção e prevenção de riscos em áreas costeiras.

Tanto as medidas de mitigação quanto medidas de adaptação são importantes no enfrentamento das mudanças climáticas que, de maneira concomitante, necessitam ser articuladas com estratégia para o direcionamento e remodelação pontual das problemáticas investigadas. Este processo torna-se complementar para o planejamento estratégico do borde costeiro da cidade de Santos. 
ISSN eletrônico 2317-8604, volume 9, número 24, 2021

\section{REFERÊNCIAS}

ANTRÓPICO. In: Michaelis. Moderno dicionário da língua portuguesa. São Paulo: Melhoramentos, 1998. Dicionários Michaelis, $2259 \mathrm{p}$.

ARRIAGADA, Carlos Andrés Hernández. Estratégias Projetuais no Território do Porto de Santos. 2012. 278 f. Tese (Doutorado) - Curso de Arquitetura e Urbanismo, Universidade Presbiteriana Mackenzie, São Paulo, 2012. Disponível em: <https://www.lab-strategy.com/cidade-porto> Acesso em: 20 abr. 2021

CONSTRUÇÃOCIVILPET. Geossintéticos. Civilização Engenharia, 2016. Disponível em: <https://civilizacaoengenheira.wordpress.com/2016/03/23/geossinteticos/>. Acesso em: 8 mai. 2021.

G1 Santos. Após ressaca, especialista analisa eficácia de bags em Santos, SP. G1 Globo - Santos e Região, 08 jul. 2019. Disponível em: <https://g1.globo.com/sp/santos-regiao/noticia/2019/07/08/apos-ressaca-especialista-analisaeficacia-de-bags-em-santos-sp.ghtml>. Acesso em: 25 abr. 2021.

G1 Santos. Forte ressaca que inundou bairros de Santos surpreendeu até especialistas. G1 Globo - Santos e Região, 23 ago. 2016a. Disponível em: <http://g1.globo.com/sp/santos-regiao/noticia/2016/08/forte-ressaca-que-inundoubairros-de-santos-surpreendeu-ate-especialistas.html>. Acesso em: 25 abr. 2021.

G1 Santos. Ressaca inunda avenida da praia em Santos e provoca transtornos. G1 Globo - Santos e Região, 21 ago. 2016b. Disponível em: <http://g1.globo.com/sp/santos-regiao/noticia/2016/08/ressaca-inunda-avenida-da-praiaem-santos-e-causa-bloqueios-no-canal-

6.html\#: :text=Uma\%20forte\%20ressaca\%20inundou\%20as,bairro\%20da\%20Ponta\%20da\%20Praia>. Acesso em: 25 abr. 2021.

GIRELI, T. Z., GARCIA, P. D., CAMPOS R. M. NOTA tÉCNICA 1: PROPOSTA DE PROJETO PILOTO PARA MONITORAMENTO E CONTENÇÃO DA EROSÃO NA PONTA DA PRAIA - SANTOS (SP). Universidade Estadual de Campinas - UNICAMP. Faculdade de Engenharia Civil, Arquitetura e Urbanismo. Departamento de Recursos Hídricos. Campinas, 2017.

IOUSP. Erosão Costeira - IOUSP. Disponível em: <https://www.io.usp.br/index.php/ocean-coast-res/50-portugues /publicacoes/series-divulgacao/gestao-costeira/823-erosaocosteira.html\#: :text=A\%20eros\%C3\%A30\%20costeira\%20ocorre\%20em,global\%20(Bird\%2C\%202008).\&text=A\%20 eros\%C3\%A30\%20ocorre\%20quando\%20o,\%C3\%A9\%20uma\%20consequ\%C3\%AAncia\%20deste\%20processo.>. Acesso em: 7 mai. 2021.

IPCC, 2014: Summary for Policymakers. In: Climate Change 2014: Mitigation of Climate Change. Contribution of Working Group III to the Fifth Assessment Report of the Intergovernmental Panel on Climate Change [Edenhofer, O., R. Pichs-Madruga, Y. Sokona, E. Farahani, S. Kadner, K. Seyboth, A. Adler, I. Baum, S. Brunner, P. Eickemeier, B. Kriemann, J. Savolainen, S. Schlömer, C. von Stechow, T. Zwickel and J.C. Minx (eds.)]. Cambridge University Press, Cambridge, United Kingdom and New York, NY, USA. Disponível em: <https://www.ipcc.ch/report/ar5/wg3/> Acesso em: 15 sbr. 2021

IPCC, 2019: Summary for Policymakers. In: IPCC Special Report on the Ocean and Cryosphere in a Changing Climate [H.-O. Pörtner, D.C. Roberts, V. Masson-Delmotte, P. Zhai, M. Tignor, E. Poloczanska, K. Mintenbeck, A. Alegría, M. Nicolai, A. Okem, J. Petzold, B. Rama, N.M. Weyer (eds.)]. In press. Disponível em: <https://www.ipcc.ch/srocc/> Acesso em: 15 abr. 2021

MORFOLOGIA. In: Michaelis. Moderno dicionário da língua portuguesa. São Paulo: Melhoramentos, 1998. Dicionários Michaelis, $2259 \mathrm{p}$.

NAKAMURA, J. Geobags são solução de baixo impacto ambiental para obras de contenção. AECweb, c2021. Disponível em: <https://www.aecweb.com.br/revista/materias/geobags-sao-solucao-de-baixo-impacto-ambientalpara-obras-de-contencao/20357>. Acesso em: 8 mai. 2021.

OLIVEIRA, E. C. O. Erosão costeira na Ponta da Praia, Santos - SP, e as modificações antrópicas nos sistemas marinhos e estuarino da região. Departamento de Ciências do Mar, Instituto de Saúde e Sociedade, Campus Baixada Santista, Universidade Federal de São Paulo, 2017. 


\section{Periódica Téenica e Cientifica \\ Cidades Verdes}

ISSN eletrônico 2317-8604, volume 9, número 24, 2021

OLIVEIRA, Leonardo Lameira. TFG Proposta urbanística da área de assoreamento da proteção da costa da Ponta da Praia. 2018

PION, L. M., BERNARDINO, J. C. M., ZAMBON R. C. Estudo hidráulico conceitual para definição de layout geral de obra de proteção da costa na região da Ponta da Praia, Santos, SP. Estudo e pesquisa de obras para a otimização morfológica, náutica e logística do canal de acesso do Porto de Santos. FCTH - Fundação Centro Tecnológico de Hidráulica. Relatório Técnico n 1. CODESP. 2017.

PMMCS. Plano Municipal de Mudanças do Clima de Santos. 2016. Disponível em: < https://www.santos.sp.gov.br/?q =projeto/plano-municipal-de-mudanca-do-clima-de-santos\#: :text=0\%20Plano\%20Municipal\%20de\%20Mudan\%C3 \%A7as,coloca\%20diante\%20de\%20um\%20desafio.> Acesso em: 28 abr. 2021

PORTO GENTE. Onshore. 2016. Disponível em: https://portogente.com.br/portopedia/84523-onshore. Acesso em: 8 mai. 2021.

PREFEITURA de Santos. Muretas acompanham andanças e vida de santistas. 2019. Disponível em: <https://www.santos.sp.gov.br/?q=noticia/muretas-acompanham-andancas-e-vida-de-santistas $>$. Acesso em: 7 mai. 2021.

RESSACA em Santos, 21 de agosto de 2016. HidroMares, 22 ago. 2016. SISMO ${ }^{\circledR}$. Disponível em: <https://hidromares.com.br/blog/blog-ressaca-em-santos-21-de-agosto-de-2016/>. Acesso em: 25 abr. 2021.

SEDIMENTO. In: Michaelis. Moderno dicionário da língua portuguesa. São Paulo: Melhoramentos, 1998. Dicionários Michaelis, $2259 \mathrm{p}$.

SOBRE NÓS. HidroMares, 2021. Disponível em: <https://hidromares.com.br/sobre-nos/>. Acesso em: 25 abr. 2021.

SUGUIO, K. Rochas sedimentares. São Paulo: Edgard Blucher, 500 pp, 1980.

UNEP. Adaptation Gap Report 2020. 2021. United Nations Environment Programme. Disponível em: <https://www. unep.org/adaptation-gap-report-2020> Acesso em: 16 abr. 2021

U.S. ARMY. Coastal Engineering Manual. Coastal and Hydraulic Laboratory, Vicksburg, 2006.

VENANCIO, K. K., GITELI T. Z., GARCIA P. D. EVOLUÇÃO DA LINHA DE COSTA NA REGIÃO DA PONT DA PRAIA EM SANTOS - SP. Anais do XXII Simpósio Brasileiro de Recursos Hídricos, Florianópolis, Brasil, 2017

WANG, Jinping; $\mathrm{CHURCH}$, John A.; ZHANG, Xuebin; et al. Reconciling global mean and regional sea level change in projections and observations. Nature Communications, v. 12, n. 1, 2021. Disponível em: <https://www.nature.com /articles/s41467-021-21265-6\#citeas>. Acesso em: 29 Apr. 2021.

WMO, 2021. The State of the Global Climate 2020. World Meteorological Organization. Disponível em: <https://public.wmo.int/en/our-mandate/climate/wmo-statement-state-of-global-climate> Acesso em: 22 abr. 2021

WWF. Climate adaptation and climate mitigation. Disponível em: <https://www.worldwildlife.org/stories/what-sthe-difference-between-climate-change-mitigation-and-adaptation>. Acesso em: 29 abr. 2021. 